\title{
Positive expression of p53, c-erbB2 and MRP proteins is correlated with survival rates of NSCLC patients
}

\author{
YUJIN XU ${ }^{1}$, LIANCONG WANG ${ }^{2}$, XIAO ZHENG $^{1}$, GUAN LIU $^{1}$, \\ YUEZHEN WANG $^{1}$, XIAOJING LAI $^{1}$ and JIANQIANG LI ${ }^{1}$ \\ ${ }^{1}$ Department of Radiation Oncology, Zhejiang Cancer Hospital, Hangzhou 310022; ${ }^{2}$ Department of Radiation Oncology, \\ The Second Affiliated Hospital, Zhejiang University School of Medicine, Hangzhou, Zhejiang 310009, P.R.China
}

Received July 20, 2012; Accepted January 8, 2013

DOI: $10.3892 / \mathrm{mco} .2013 .72$

\begin{abstract}
The incidence of lung cancer is one of the leading causes of mortality. This study aimed to investigate the prognostic and predictive importance of p53, c-erbB2 and multidrug resistance proteins (MRP) expression and its correlation with clinicopathological characteristics of patients with non-small cell lung cancer (NSCLC). Expression of p53, c-erbB2 and MRP proteins in 152 tumor samples from resected primary NSCLCs was detected by immunohistochemical staining. The correlation of proteins, survival and clinicopathological characteristics was investigated in 152 patients undergoing potentially curative surgery. The positive rates of $\mathrm{p} 53$, c-erbB2 and MRP expression were 53.9 (82/152), 44.1 (67/152) and $43.4 \%$ (66/152), respectively. Overall survival rates of patients were markedly correlated with the overexpression of p53, c-erbB2 and MRP proteins. One, 2- and 3-year survival rates of patients exhibiting a positive expression of these proteins were $72.6,54.8$ and $32.2 \%$, respectively. These rates were lower compared with those of patients with a negative expression of these proteins $(92.1,78.5$ and $63.4 \%)(\mathrm{P}=0.02,0.01$ or 0.00 , respectively). Results of Cox's regression analysis showed that c-erbB2 expression and cell differentiation were independent prognostic factors in patients with NSCLC. These findings suggest that the positive expression of p53, c-erbB2 and MRP proteins is correlated with the survival rates of NSCLC patients. Detection of positive p53, c-erbB2 and MRP expression may be a useful predictive indicator of prognosis. Positive c-erbB2 expression is an independent prognostic factor, with a potential to be used as a predictive indicator of chemotherapy efficacy in NSCLC patients.
\end{abstract}

Correspondence to: Professor Lianchong Wang, Department of Radiation Oncology, The Second Affiliated Hospital, Zhejiang University School of Medicine, Jiefang Road 88, Hangzhou, Zhejiang 310009, P.R.China

E-mail: yanchengren99@yahoo.cn

Key words: non-small cell lung cancer, p53, multidrug resistance proteins, c-erbB2

\section{Introduction}

Lung cancer is one of the leading causes of mortality, with a curing rate of only $\sim 13 \%$ (1). Non-small cell lung cancers (NSCLC) account for $80 \%$ of lung cancers. Approximately $75-80 \%$ of NSCLC patients, when diagnosed, are already in the late stage of the cancer. Surgery is the main treatment for NSCLC patients in clinical stage I-IIIa. Following surgery, administration of adjuvant chemotherapy (combination of two platinum drugs) may lead to significant survival benefits (2), even though $30-60 \%$ of patients receiving adjuvant chemotherapy experience tumor recurrence or distant metastasis (3). Multidrug resistance (MDR) constitutes a challenge with regard to effective chemotherapeutic interventions. The occurrence of MDR, regardless of whether it is congenital or acquired, is a serious challenge for effective administration of NSCLC treatments.

p53 tumor suppressor gene is a multifunctional protein that is involved in the regulation of cell cycles, apoptosis, gene transcription, stress response and DNA repair. Previous studies focused on the correlation between $\mathrm{p} 53$ protein expression and cisplatin-based chemotherapy for late-stage NSCLC patients. In their study, Tsao et al (4) observed that among 253 NSCLC cases, positive p53 protein expression was more likely to be found in male and squamous cell carcinoma patients. However, Bai et al (5) observed that a high expression of p53 protein is correlated with tumor invasion status in hilar, pericardium, blood vessels and thrombosis.

Multidrug resistance proteins (MRP), including MRP1 and MRP2, are key members of the ATP-binding transporter superfamily ( $\mathrm{ABC}$ proteins). These proteins are involved in the transmembrane transportation of prokaryotic and eukaryotic cells. By regulating the $\mathrm{pH}$ in cytoplasm and organelles, MRP proteins may decrease the amount of drugs at the functioning sites and reduce the intracellular concentration of drugs, leading to drug resistance. MRP expression may be associated with drug resistance and prognosis of lung cancers (6). However, the correlation between MRP expression and lung cancer types, differentiations and clinical stages remains to be clarified.

Overexpression of c-erbB 2 protein expression may be detected in a variety of malignancies, including NSCLC. c-erbB2 protein is a marker of endogenous MDR, which can be used as an independent predictor (7). c-erbB2 protein 
overexpression is associated with mutations in chromosome 17q21 locus (8). Turken et al (9) demonstrated that $35 \%$ of NSCLC cases were associated with a high c-erbB2 protein expression. A high c-erbB2 protein expression is frequently detected in lung adenocarcinoma tissues in stage IIIb-IV $(\mathrm{P}=0.04)$. NSCLC patients with a positive c-erbB2 protein expression are prone to recurrence and metastasis following treatment. Therefore, a high c-erbB2 protein expression is an indicator of tumor progression $(8,9)$, but a high c-erbB2 protein expression is not associated with the sensitivity of chemotherapy (9).

In this study, immunohistochemical methods were used to investigate expression levels of three drug resistance-associated proteins (p53, c-erbB2 and MRP) in NSCLC tissues. The correlation between expression levels of p53, c-erbB2 and MRP and the clinicopathological characteristics of NSCLC, as well as the prognostic significance of these protein expressions, was investigated.

\section{Materials and methods}

Patients. In total, 152 NSCLC samples were confirmed by surgery and pathological detection. Inclusion criteria were: i) pathologically proven NSCLC cells; ii) primary lung cancer cases; iii) no adjuvant radiotherapy or chemotherapy received prior to surgery; iv) no distant metastasis found prior to surgery and v) no serious heart and lung diseases or other combined diseases diagnosed (Table I).

Immunohistochemistry (IHC). Tissue samples were fixed with formaldehyde solution, embedded in paraffin, followed by regular $(4 \mu \mathrm{m})$ slicing. IHC was performed by the S-P method, as per the manufacturer's instructions, using p53, c-erbB2 and MRP mouse anti-human monoclonal antibodies and the S-P immunohistochemistry kit (Kit-9710; Maixin Biotechnology, Fujian, China). Samples were treated under the same conditions, including staining and 3,3'-diaminobenzidine (DAB) coloring. Lung sections with known protein expression were used as positive controls under the same conditions. Phosphate-buffered saline (PBS) was used as the blank control for primary antibodies. Normal mouse serum was used as the negative control for primary antibodies. For each immunohistochemical staining sample, 10 high-power views (magnification, x200) were randomly selected for microscopic observation.

Criteria for p53 protein staining were (10): cells without nucleus-stained particles were considered negative, while cells with nucleus-stained particles were considered positive. For the tissue samples: i) if $<30 \%$ of the cells were positive, the tissues were considered to be weak positive; ii) if $30-70 \%$ of the cells were positive, the tissues were considered to be moderately positive and iii) if $>70 \%$ of the cells were positive, the tissues were considered to be strongly positive. MRP and c-erbB2 protein staining was analyzed based on the Hercep score $(7,11)$, as recommended by the Food and Drug Administration (FDA). Staining scores were described as: 0-1, negative; $1-2$, weakly positive and 2-3, strongly positive.

Statistical analysis. Data were analyzed using the SPSS 16.0 software. Survival rate analyses were performed using the
Kaplan-Meier method. Sample rates were compared using the $\chi^{2}$ test. Single-factor analyses were carried out using the log-rank test. Multivariate analyses were performed using Cox's regression analysis. $\mathrm{P}<0.05$ was considered to indicate a statistically significant difference.

\section{Results}

Expression of p53, c-erbB2 and MRP proteins in NSCLC cells. In this study, correlations between the survival rates of 152 NSCLC patients and positive expression of p53, c-erbB2 and MRP proteins in NSCLC tissues were investigated. Positive expression of p53, c-erbB2 and MRP was detected by IHC (Fig. 1). IHC staining results indicated that of the 152 NSCLC cases, the positive expression of p53, c-erbB2 and MRP proteins was 53.9 (82/152), 44.1 (67/152) and 43.4\% (66/152), respectively. Spearman's rank correlation coefficient revealed a correlation in the expression of the three proteins in NSCLC tissues. The r-values between p53 and MRP, and those between p53 and c-erbB-2 were $0.248(\mathrm{P}=0.019)$ and $0.335(\mathrm{P}=0.002)$, respectively. The r-values between MRP and c-erbB-2 were $0.321(\mathrm{P}=0.005)$.

Correlations between p53, c-erbB2, MRP expression and clinicopathological characteristics of NSCLC. p53 protein expression in NSCLC tissues was markedly correlated with patient gender, cancer cell differentiation, clinical stages of NSCLC and lymph node metastasis $(\mathrm{P}<0.05$ and $\mathrm{P}<0.01)$ (Table I). A positive expression rate of MRP was markedly higher in lung adenocarcinomas $(67.6 \%)$ compared with lung squamous cell carcinoma $(33.0 \%)(\mathrm{P}<0.05)$. However, c-erbB2 expression was not correlated with the clinicopathological characteristics of NSCLC $(\mathrm{P}>0.05)$.

Correlations between expression of p53, c-erbB2 and MRP proteins and the survival rates of NSCLC patients. The combination of positive $\mathrm{p} 53, \mathrm{c}$-erbB2 and MRP expression indicated poor prognosis (Table II). One, 2- and 3-year survival rates of patients with a positive expression of these three proteins were markedly lower compared with those of patients with a negative expression of the three proteins $(\mathrm{P}=0.02,0.01$ and 0.00 , respectively).

Patients with a positive expression of two of the three proteins had lower 1-, 2- and 3-year survival rates compared with those of patients with a positive expression of one or a negative expression of two proteins $(\mathrm{P}=0.02$ and $\mathrm{P}=0.01$, respectively).

Correlations between expression of p53, c-erbB2 and MRP proteins and the cumulative survival rates of NSCLC patients receiving surgery. Correlations between expression of $\mathrm{p} 53$, c-erbB2 and MRP proteins and the cumulative survival rates of NSCLC patients receiving surgery were also investigated. The cumulative 1-, 2- and 3-year survival rates of patients with a positive expression of $\mathrm{p} 53$, c-erbB2, and MRP proteins were markedly lower compared with those of patients with a negative expression of the three proteins $(\mathrm{P}<0.05)$ (Table III). Patients with a negative expression of the three proteins had the highest survival rates. Patients with a positive expression of one or two proteins had mediate survival rates, while patients 
Table I. Correlation between expression of $\mathrm{p} 53, \mathrm{MRP}$ and c-erB2 proteins and clinicopathological characteristics of NSCLC patients.

\begin{tabular}{|c|c|c|c|c|c|c|c|}
\hline \multirow{2}{*}{$\begin{array}{l}\text { Clinicopathological } \\
\text { characteristics }\end{array}$} & \multirow[b]{2}{*}{ No. } & \multicolumn{2}{|c|}{ p53 } & \multicolumn{2}{|c|}{ MRP } & \multicolumn{2}{|c|}{ c-erbB2 } \\
\hline & & Positive (\%) & $\chi^{2}$ & Positive $(\%)$ & $\chi^{2}$ & Positive (\%) & $\chi^{2}$ \\
\hline \multicolumn{8}{|l|}{ Gender } \\
\hline Male & 127 & $73(57.5)$ & $54(42.5)$ & $55(43.3)$ & & & \\
\hline Female & 25 & $9(36.0)$ & $3.879^{\mathrm{a}}$ & $12(48.0)$ & 0.255 & $12(48.0)$ & 0.214 \\
\hline \multicolumn{8}{|l|}{ Age (years) } \\
\hline$\leq 59$ & 69 & $32(46.4)$ & $30(43.5)$ & $35(50.7)$ & & & \\
\hline$>59$ & 83 & $50(60.2)$ & 2.915 & $36(43.4)$ & 0.000 & $32(38.6)$ & 1.237 \\
\hline \multicolumn{8}{|l|}{ Pathological types } \\
\hline Squamous cell carcinoma & 97 & $35(36.1)$ & $32(33.0)$ & $46(47.4)$ & & & \\
\hline Adenocarcinoma & 37 & $15(40.5)$ & $25(67.6)$ & $13(35.1)$ & & & \\
\hline Others & 18 & $5(27.8)$ & 1.520 & $9(50.0)$ & $7.545^{\mathrm{a}}$ & $8(44.4)$ & 0.978 \\
\hline \multicolumn{8}{|l|}{ Differentiation } \\
\hline High and medium & 99 & $43(43.4)$ & $38(38.4)$ & $51(51.5)$ & & & \\
\hline Low & 53 & $39(73.6)$ & $12.63^{\mathrm{b}}$ & $28(52.8)$ & 2.932 & $16(30.2)$ & 2.548 \\
\hline \multicolumn{8}{|l|}{ TNM staging } \\
\hline I-II & 99 & $46(46.5)$ & $49(49.5)$ & $50(50.5)$ & & & \\
\hline III & 53 & $36(67.9)$ & $6.399^{\mathrm{a}}$ & $17(32.1)$ & 3.125 & $17(32.1)$ & 3.087 \\
\hline \multicolumn{8}{|l|}{ Lymph node metastasis } \\
\hline Yes & 78 & $51(65.4)$ & $32(41.0)$ & $29(37.2)$ & & & \\
\hline No & 74 & $31(41.9)$ & $8.436^{\mathrm{b}}$ & $34(45.9)$ & 0.374 & $38(51.4)$ & 1.963 \\
\hline \multicolumn{8}{|l|}{ Vascular tumor thrombus } \\
\hline Yes & 17 & $7(41.2)$ & $5(29.4)$ & $6(35.3)$ & & & \\
\hline No & 135 & $75(55.6)$ & 1.257 & $61(45.2)$ & 1.529 & $61(45.2)$ & 1.102 \\
\hline \multicolumn{8}{|l|}{ Margin } \\
\hline Negative & 148 & $79(53.4)$ & $65(43.9)$ & $66(44.6)$ & & & \\
\hline Positive & 4 & $3(75.0)$ & 0.733 & $1(25.0)$ & 0.567 & $1(25.0)$ & 0.379 \\
\hline
\end{tabular}

${ }^{\mathrm{a}} \mathrm{P}<0.05,{ }^{\mathrm{b}} \mathrm{P}<0.01$. NSCLC, non-small cell lung cancer; MRP, multidrug resistance proteins.

with a positive expression of all three proteins had the lowest survival rates. Survival rates in the subgroups were statistically significant (Fig. 2, P<0.05).

Correlations between expression of p53,c-erbB2 and $M R P$ proteins and the cumulative survival rates of NSCLC patients receiving surgery and chemotherapy. In patients who received surgery plus chemotherapy following surgery, and had a positive expression of MRP and c-erbB2 protein, the cumulative 1-, 2- and 3-year survival rates were markedly lower compared with those of patients with a negative expression of these proteins (Table III, $\mathrm{P}<0.05$ ). However, the survival rate differences of patients with a positive or negative p53 expression were not statistically significant (Table III, $\mathrm{P}=0.82$ ). Cumulative survival rates of patients with a negative expression of MRP and c-erbB2 were higher compared with those of patients with a positive expression of the two proteins. Additionally, patients with a positive expression of either MRP or c-erbB2 had cumulative survival rates between them. The results of the comparisons were statistically significant (Fig. 3, $\mathrm{P}=0.01$ ).
Cox multi-element analyses. Age, gender, pathological types, cancer cell differentiation and other clinical or pathological characteristics, as well as expression patterns of p53, c-erbB2 and MRP proteins were analyzed in NSCLC patients, using the multi-element Cox model. Cancer cell differentiation and c-erbB2 expression were identified as two independent predictors of the prognosis of NSCLC patients suitable for surgery (95\% CI, $\mathrm{P}=0.000$ and 0.029 ).

\section{Discussion}

MDR is the key reason for the poor efficacy of chemotheraphy in NSCLC. Several factors are involved in MDR development. The MRP phenotypes of various types of lung cancers are different. The mechanisms of NSCLC MDR remain to be clarified, but are possibly associated with changes in the expression levels of a variety of proteins resulting in the process of tumor formation. p53, MRP and c-erbB2 are three MDR-regulating proteins. In this study, we observed that the three proteins are correlated with the efficacy of surgery and chemotherapy in NSCLC patients. 
Table II. Correlation between expression of p53, MRP and c-erbB2 in tumor tissues and survival rates of NSCLC patients.

\begin{tabular}{|c|c|c|c|c|c|c|c|}
\hline \multirow[b]{2}{*}{ Variables } & \multirow[b]{2}{*}{ No. } & \multicolumn{6}{|c|}{ NSCLC survival rates (146 cases) } \\
\hline & & 1 -year $(\%)$ & P-value & 2-year (\%) & P-value & 3 -year (\%) & P-value \\
\hline \multicolumn{8}{|l|}{ MRP } \\
\hline Negative & 82 & 82.3 & 0.35 & 75.8 & 0.04 & 54.7 & 0.04 \\
\hline Positive & 64 & 77.6 & 60.2 & 35.6 & & & \\
\hline \multicolumn{8}{|l|}{ c-erbB2 } \\
\hline Negative & 81 & 87.4 & 0.07 & 73.3 & 0.10 & 50.4 & 0.03 \\
\hline Positive & 65 & 79.2 & 65.4 & 36.1 & & & \\
\hline \multicolumn{8}{|l|}{ p53 } \\
\hline Negative & 67 & 86.5 & 0.14 & 71.6 & 0.11 & 59.8 & 0.09 \\
\hline Positive & 79 & 81.3 & 67.2 & 54.3 & & & \\
\hline \multicolumn{8}{|l|}{ p53, MRP, c-erbB2 } \\
\hline All negative & 28 & 92.1 & 0.02 & 78.5 & 0.01 & 63.4 & 0.00 \\
\hline \multicolumn{8}{|c|}{ p53, MRP, c-erbB2 } \\
\hline All positive & 23 & 72.6 & 54.8 & 32.2 & & & \\
\hline \multicolumn{8}{|l|}{ p53 and MRP } \\
\hline All negative & 16 & 88.3 & 0.08 & 76.5 & 0.03 & 61.8 & 0.02 \\
\hline \multicolumn{8}{|l|}{ p53 and MRP } \\
\hline All positive & 18 & 75.2 & 57.1 & 34.2 & & & \\
\hline \multicolumn{8}{|l|}{ p53 or MRP } \\
\hline Single positive & 35 & 83.5 & 69.3 & 51.2 & & & \\
\hline \multicolumn{8}{|l|}{ p53 and c-erbB2 } \\
\hline All Negative & 12 & 90.2 & 0.13 & 74.8 & 0.07 & 61.7 & 0.02 \\
\hline \multicolumn{8}{|l|}{ p53 and c-erbB2 } \\
\hline All positive & 15 & 76.4 & 60.9 & 35.3 & & & \\
\hline \multicolumn{8}{|l|}{ p53 or c-erbB2 } \\
\hline Single positive & 39 & 84.3 & 71.4 & 56.5 & & & \\
\hline \multicolumn{8}{|l|}{ MRP and c-erbB2 } \\
\hline All negative & 23 & 88.6 & 0.08 & 76.2 & 0.03 & 58.7 & 0.01 \\
\hline \multicolumn{8}{|l|}{ MRP and c-erbB2 } \\
\hline All positive & 11 & 74.2 & 58.1 & 32.6 & & & \\
\hline \multicolumn{8}{|l|}{ MRP and c-erbB2 } \\
\hline Single positive & 28 & 82.5 & 67.3 & 43.4 & & & \\
\hline
\end{tabular}

$\chi^{2}$ test. NSCLC, non-small cell lung cancer; MRP, multidrug resistance proteins.
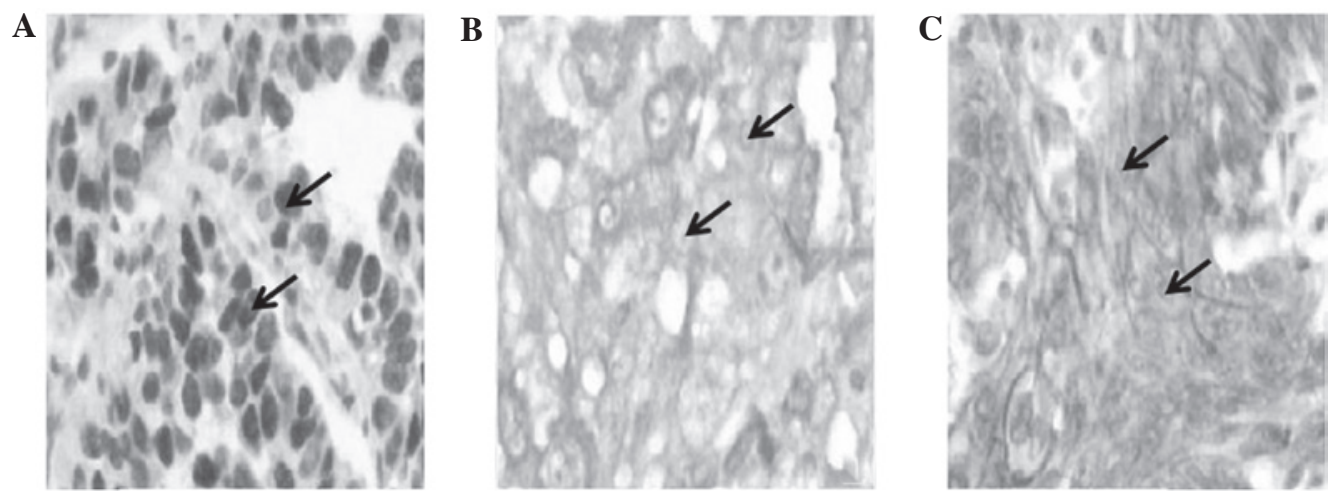

Figure 1. Positive expression (as indicated by arrows) of p53, MRP and c-erbB2 proteins in NSCLC tissues (S-P, magnification, x200). (A) p53, (B) MRP and (C) c-erbB2. NSCLC, non-small cell lung cancer; MRP, multidrug resitance proteins. 
Table III. Correlation between expression of p53, MRP and c-erbB2 in tumor tissues and survival rates of NSCLC patients undergoing surgery only or surgery plus chemotherapy.

\begin{tabular}{|c|c|c|c|c|c|c|c|c|}
\hline \multirow[b]{2}{*}{ Variables } & \multicolumn{4}{|c|}{ Surgery } & \multicolumn{4}{|c|}{ Surgery and chemotherapy after surgery } \\
\hline & $\begin{array}{c}1 \text {-year } \\
\text { survival }(\%)\end{array}$ & $\begin{array}{c}2 \text {-year } \\
\text { survival (\%) }\end{array}$ & $\begin{array}{c}\text { 3-year } \\
\text { survival }(\%)\end{array}$ & P-value & $\begin{array}{c}1 \text {-year } \\
\text { survival }(\%)\end{array}$ & $\begin{array}{c}\text { 2-year } \\
\text { survival }(\%)\end{array}$ & $\begin{array}{c}\text { 3-year } \\
\text { survival (\%) }\end{array}$ & P-value \\
\hline \multicolumn{9}{|l|}{ p53 } \\
\hline Positive & 79.5 & 59.0 & 43.6 & 0.03 & 82.5 & 70.0 & 62.5 & 0.82 \\
\hline Negative & 84.8 & 69.7 & 58.7 & 94.1 & 73.5 & 61.8 & & \\
\hline \multicolumn{9}{|l|}{ MRP } \\
\hline Positive & 76.4 & 61.3 & 34.9 & 0.04 & 78.2 & 58.3 & 36.9 & 0.03 \\
\hline Negative & 79.7 & 74.5 & 49.6 & 84.6 & 76.7 & 59.4 & & \\
\hline \multicolumn{9}{|l|}{ c-erbB2 } \\
\hline Positive & 74.2 & 62.2 & 32.7 & 0.04 & 83.6 & 70.7 & 38.7 & 0.01 \\
\hline Negative & 80.5 & 72.4 & 48.9 & 94.3 & 74.1 & 52.9 & & \\
\hline
\end{tabular}

$\chi^{2}$ test. NSCLC, non-small cell lung cancer; MRP, multidrug resistance proteins.

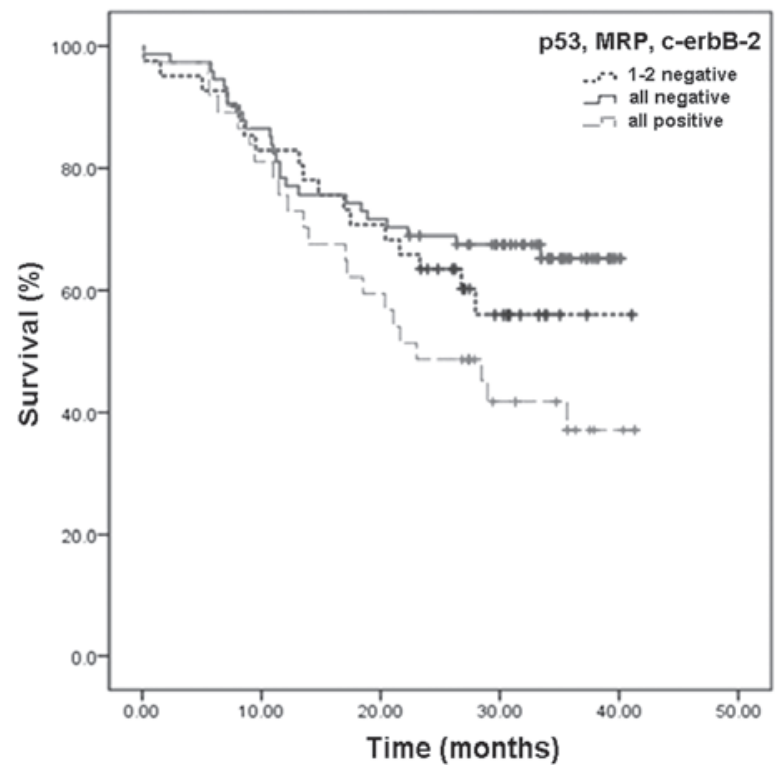

Figure 2. Survival curves of patients who underwent surgery with various expression patterns of p53, multidrug resistance proteins (MRP), and c-erbB-2 proteins. Patients with a negative expression of the three proteins had the highest survival rates, while patients with a positive expression of the three proteins had the lowest survival rates $(\mathrm{P}<0.05)$.

In this study, IHC was used to detect p53 expression in 152 NSCLC cases. The findings show that the positive rate of p53 expression in NSCLC cases was 53.9\%. p53 protein expression was correlated with NSCLC patient gender, cytological grades, clinical stages, lymph node metastasis and other clinical characteristics $(\mathrm{P}<0.05)$, but did not correlate with pathological types. In their study, Rusch et al (10) found that NSCLC patients with a positive expression of p53 protein are less sensitive to cisplatin compared with patients with a negative expression of $\mathrm{p} 53$ protein, a negative correlation. Sengupta et al (12) reported that overexpression of p53 protein

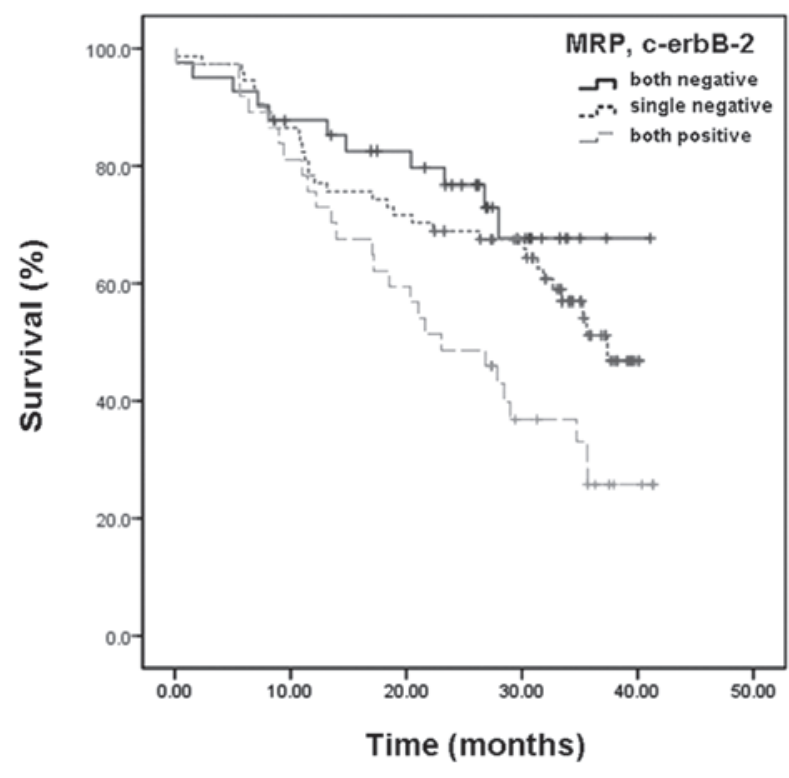

Figure 3. Survival curves of patients who underwent surgery and received chemotheraphy with various expression patterns of multidrug resistance (MRP) and c-erbB-2 proteins. Cumulative survival rates of patients with a negative expression of MRP and c-erbB2 were higher compared with those patients with a positive expression of the two proteins. Patients with a positive expression of either MRP or c-erbB2 had cumulative survival rates $(\mathrm{P}=0.01)$.

may affect the efficacy of chemotherapy, leading to poor prognosis of NSCLC. However, Huang et al (13) observed that the chemotherapeutic efficacy of late-stage NSCLC patients with a negative expression of $\mathrm{p} 53$ protein was less than that of patients with a positive p53 expression, a positive correlation. However, this positive correlation is not adequate to be statistically significant. Our studies showed that 1-, 2- and 3-year survival rates of patients with a positive expression of p53 protein were not statistically different from those of patients with a negative $\mathrm{p} 53$ protein expression $(\mathrm{P}=0.82)$, indicating that the post-surgery chemotherapeutic efficacy did not correlate with 
p53 protein expression. These inconsistencies may be due to the two-way regulation of chemotherapy sensitivity by p53 as reported previously (14). In their study, Lee et al (15) reported that a positive expression of p53 protein is a good indicator of early prognosis in resectable NSCLC cases. However, Kwiatkowski et al (16) and Ebina et al (17) demonstrated that p53 protein overexpression predicts a poor prognosis for NSCLC patients in early stages. In this study, the 1-, 2- and 3-year survival rates of patients, who only underwent surgery and had a positive expression of p53, were lower compared to those of patients with a negative expression of p53. This difference is statistically significant $(\mathrm{P}=0.03)$. Although a positive p53 expression is negatively correlated with the prognosis of NSCLC, the Cox multi-element analyses indicated that p53 is not an independent predictor of the prognosis of NSCLC patients.

Filipits et al (18) found that NSCLC patients suitable for surgery had a positive MRP1 expression rate of $47 \%$ and a positive MRP2 expression of $40 \%$. The overall survival rates of NSCLC patients with a positive MRP2 expression were markedly shorter compared with those of patients with a negative MRP2 expression $(\mathrm{P}=0.007)$, suggesting that MRP2 protein expression may be an indicator of poor prognosis of NSCLC patients suitable for surgery. However, MRP1 expression did not correlate with survival period. MRP1 and MRP2 are not significant for predicting the efficacy of platinum-containing chemotherapy. Our results indicate that in NSCLC tumor tissues, MRP protein had a positive expression rate of $43.4 \%$ $(66 / 152)$, which is markedly correlated with pathological types and lymph node metastasis $(\mathrm{P}<0.05)$. The positive MRP protein expression rate in lung adenocarcinoma was $67.6 \%$ (25/37), markedly higher compared with that of squamous cell carcinoma $(33.0 \%, 32 / 97)$, which was markedly different $(\mathrm{P}<0.05)$. The 1-, 2- and 3-year survival rates of patients with a positive MRP expression were markedly lower compared with those of patients with a negative MRP expression, suggesting poor prognosis of NSCLC patients with a positive MRP expression. However, the Cox multi-element analyses suggest that MRP is not an independent predictor of the prognosis of NSCLC patients.

Our findings suggest that the 1-, 2- and 3-year survival rates of patients, who received surgery and chemotherapy, and had positive c-erbB2 protein expression, were markedly lower compared with those of patients with a negative c-erbB2 expression $(\mathrm{P}=0.01)$, suggesting that NSCLC patients with a positive c-erbB2 expression may be resistant to platinumcontaining chemotherapy. Overexpression of c-erbB2 protein in NSCLC tissues may be a prognostic indicator of tumor progression. Similarly, the Cox multi-element analyses suggest that c-erbB2 is an independent predictor of the prognosis of NSCLC patients.

Findings of this study have shown that a positive expression of the three proteins in NSCLC patients indicates a poor prognosis, as the 1-, 2- and 3-year survival rates were 72.6, 54.8 and $32.2 \%$, respectively, which were markedly lower compared with those of patients with a negative expression of the three proteins $(92.1,78.5$ and $63.4 \%, \mathrm{P}=0.02,0.01$ and 0.00$)$. The 3 -year survival rates of patients with a positive expression of two proteins were lower compared with those of patients with a positive expression of one protein or a negative expression of the two proteins $(\mathrm{P}=0.02$ and $\mathrm{P}=0.01)$. Utilization of $\mathrm{p} 53$, c-erbB2 and MRP as a three-indicator combination or of MRP and c-erbB2 as a two-indicator combination, are useful for the prognostic evaluation of the surgical and chemotherapeutic efficacies of NSCLC patients.

\section{Acknowledgements}

This study was supported by the Traditional Chinese Medicine project of the Zhejiang Province (grant no. 008CA036).

\section{References}

1. Bunn PA: Future directions in clinical research for lung cancer. Chest 106: 399-407, 1994.

2. Arriagada R, Bergman B, Dunant A, et al: Cisplatin-based adjuvant chemotherapy in patients with completely resected non-small cell lung cancer. N Engl J Med 350: 351-360, 2004.

3. Mountain CF: Revisions in the international system for staging Lung Cancer. Chest 111: 1710-1717, 1997.

4. Tsao MS, Aviel-Ronen S, Ding K, et al: Prognostic and predictive importance of p53 and RAS for adjuvant chemotherapy in non-small cell lung cancer. J Clin Oncol 25: 5240-5247, 2007.

5. Bai H, Zhang XY, Ji H, et al: Expression and the clinical significance of 553 and $\mathrm{nm} 23$ in non-small cell lung cancers. J Prac Oncol 19: 497-500, 2004.

6. Ota E, Abe Y, Oshika Y, et al: Expression of the multidrug resistance-associated protein (MRP) gene in non-small cell lung cancer. Br J Cancer 72: 550-554, 1995.

7. $\mathrm{Bu} \mathrm{H}$ and Pang ZG: Research progress of C-erbB-2 gene in breast cancers. Gene News 1: 12, 2001.

8. Kristiansen G, Yu Y, Petersen S, et al: Overexpression of c-erbB2 protein correlates with disease-stage and chromosomal gain at the c-erbB2 locus in non-small cell lung cancer. Eur J Cancer 37: 1089-1095, 2001.

9. Turken O, Kunter E, Cermik H, et al: Prevalence and prognostic value of c-erbB2 expression in non-small cell lung cancer (NSCLC). Neoplasma 50: 257-261, 2003.

10. Rusch V, Klimstra D, Venkatraman E, et al: Aberrant p53 expression predicts clinical resistance to cisplatin-based chemotherapy in locally advanced non-small cell lung cancer. Cancer Res 55: 5038-5042, 1995.

11. Izquierdo MA, Shoemaker RH, Flens MJ, et al: Overlapping phenotypes of multidrug resistance among panels of human cancer cell lines. Int J Cancer 65: 230-237, 1996.

12. Sengupta $S$ and Harris CC: p53: traffic cop at the crossroads of DNA repair and recombination. Nat Rev Mol Cell Biol 6: 44-55, 2005.

13. Huang PY, Liang XM, Lin SX, et al: Correlations analysis among expression of ERCC1, metallothionein p53 and platinum resistance and prognosis in advanced non-small cell lung cancer. Chin J Cancer 23: 845-850, 2004.

14. Zhang HT: p53 and chemotherapy sensitivity. Foreign Medicine: Oncology 28: 344-347, 2001.

15. Lee JS, Yoon A, Kalapurakal SK, et al: Expression of p53 oncoprotein in non-small cell lung cancer: a favorable prognostic factor. J Clin Oncol 13: 1893-1903, 1995.

16. Kwiatkowski DJ, Harpole DH, Godleski J, et al: Molecular pathologic substaging in 244 stage I non-small cell lung cancer patients: clinical implications. J Clin Oncol 16: 2468-2477, 1998.

17. Ebina SM, Mulshine JL, Linnoila RI, et al: Relationship of p53 overexpression and up-regulation of proliferating cell nuclear antigen with the clinical course of non-small cell lung cancer. Cancer Res 54: 2496-2503, 1994.

18. Filipits M, Haddad V, Schmid K, et al: Multidrug resistance proteins do not predict benefit of adjuvant chemotherapy in patients with completely resected non-small cell lung cancer: International Adjuvant Lung Cancer Trial Biologic Program. Clin Cancer Res 13: 3892-3898, 2007. 